\title{
Probabilistic reasoning and the rhetorical reconstruction of DNA profiling evidence
}

\author{
KAREN RICHMOND*
}

\author{
Doctoral Candidate, University of Strathclyde
}

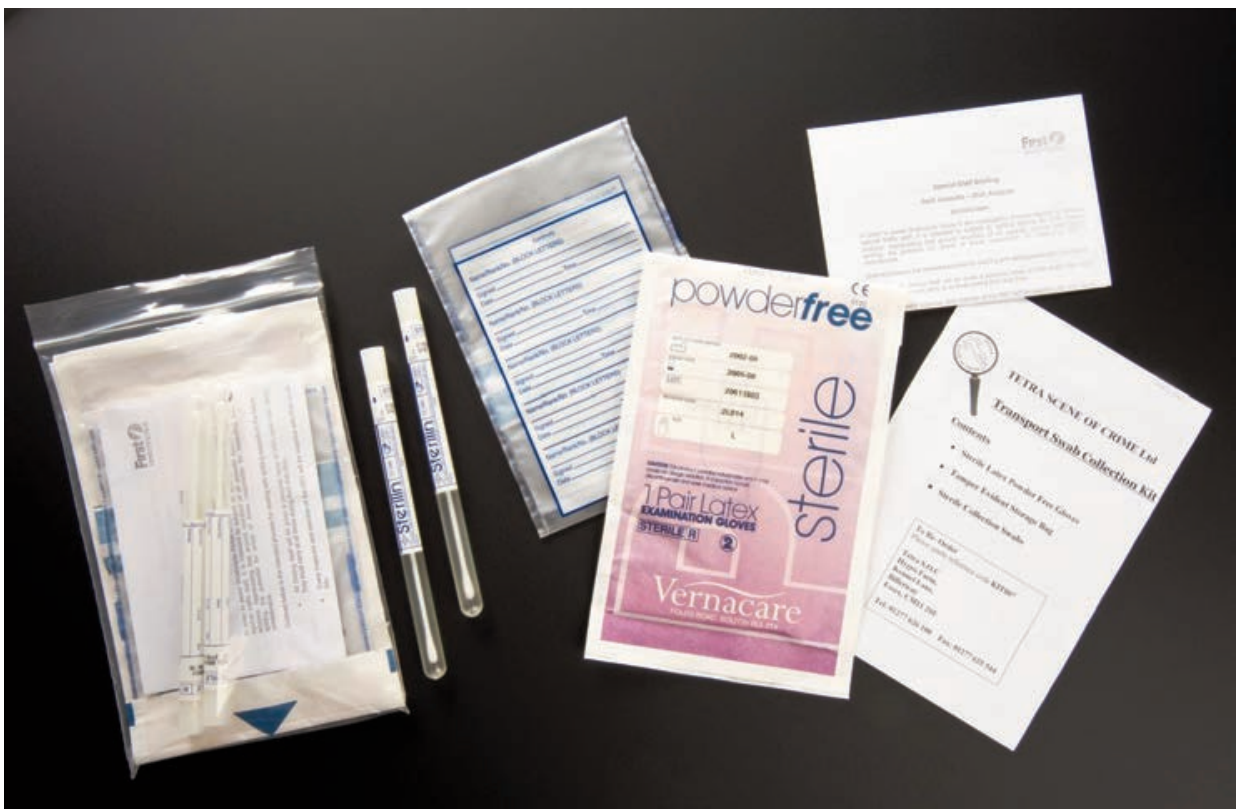

DNA swab collection kit

(C) Board of Trustees of the Science Museum $\dagger$

\section{$\underline{\text { Abstract }}$}

The co-production of forensic-scientific knowledge claims, across disciplinary boundaries, requires the mobilisation of separate (and competing) domains of expertise. The task of the interdisciplinary socio-legal researcher - exploring the collaborative practices which contribute to the construction of DNA profiling evidence - is, therefore, a complex one. It requires an understanding of the ways in which the heterogeneous groups of institutional actors, who populate the criminal justice system, set about capturing biological substrates. Further, it requires the researcher to follow a complex series of laboratory translations: technological metamorphoses, which serve to convert evidential material into graphical representations, textual inscriptions, and probabilistic outputs. This paper explores the ways in which these dynamic processes may be more comprehensively understood through the use of visual research methods. Further, it demonstrates the capacity for socio-legal modelling to contribute to interdisciplinary forensic research.

Keywords: forensic science; visual research methods; DNA profiling; rhetoric of science; probabilistic evidence.

* karen.richmond@strath.ac.uk.

$\dagger \quad<$ http://collection.sciencemuseum.org.uk/objects/co8188252/two-dna-swab-collection-kits-essex-england2006-dna-collection-kit> 
7 he DNA swab collection kit consists of a sealable transparent evidence bag and a sterile

1 'swab stick'. The collection stick comprises a sterile paper wand, with a serrated edge, which is designed to be inserted into the suspect's mouth and rubbed against the inner cheek. Alternatively, the stick may be used to swab a range of body fluids, from blood and semen to saliva. These actions deposit DNA-bearing skin cells, or fluids, onto the collection stick, which is then inserted into the sterile plastic container and deposited in the 'tamper evident' transparent bag. The collection kit is intended as an efficient tool, which can be easily used by institutional actors both within, and allied to, the criminal justice system, in order that they may successfully capture the bio-identities of suspect individuals. It is also intended to sample and document physical evidence for later use in court.

The DNA collection kit can be important in initiating a forensic investigation and may prove vital in securing a conviction. However, between collection and evaluation lie a complex series of laboratory translations, which serve to convert the evidential material into: a stable biological substrate; a graphical representation; a probabilistic output; and a textual inscription. As a socio-legal researcher exploring the construction of DNAprofiling evidence, one of my primary tasks is to reveal this hidden set of translations. And my research is predicated on the understanding that each phase of this evidential pathway (from the collection and stabilisation of trace samples to their conversion into graphical representations and statistical probabilities) is shaped by objects, processes and contextual factors - - both socially constructed and contingent - which transcend the boundaries of law and science. Interdisciplinary legal research of this kind throws up many challenges: it requires a prolonged engagement with a diverse body of scholarship; the negotiation of new vocabularies; and immersion in disparate epistemologies. It is only through such efforts that researchers can gain valuable insights into the collaborative practices of the heterogeneous groups of institutional actors who populate the criminal justice system. However, it also requires the researcher to remain open to new methodologies and research practices: methods which can produce valuable insights and serendipitous connections. The socio-legal modelling exercise is one such method.

Through the process of socio-legal modelling I was able to open up a conceptual space in which I could perceive law's instrumental use of mathematics as an applied form of aesthetics, and its deployment of Bayesian probabilities as a form of technological rhetoric. The process, and its benefits, will be discussed in detail below. However, it is worth stating that by working through the socio-legal modelling process I was ultimately able to achieve a more rigorous, and thought-provoking, analysis of the transformational grammar of forensic DNA profiling than had previously been possible.

\section{The co-production of forensic-scientific knowledge claims}

My current research focuses on a paradigmatic example of interdisciplinary forensic collaboration: the co-production of forensic-scientific knowledge claims derived from DNA profiling. DNA-profiling techniques play a central role in a growing number of criminal investigations (and subsequent proceedings). These require the mobilisation of specialist expert knowledge drawn from disparate fields - law, forensic science and research science - whose representatives collaborate with associated institutional actors within the criminal justice system, in order to produce a compelling form of probabilistic evidence which appears to conform to progressive representations of scientific and technological advance. However, it is important to note that:

... standard framings [of scientific practice] converge in their assumption that science and, to a lesser extent, technology possess an inner logic, an autonomous 
framework of validation and control, that operates irrespective of the law and does not need to be subjected to the law's normative concerns or institutional practices. ${ }^{1}$

DNA-profiling evidence does not simply present itself, as a statistical inscription, at the administrative border of the courtroom. The final conversion to a 'likelihood ratio' is actually the ultimate step in a complex series of transformations (from material sample, to stabilised laboratory substrate, graphical representation and probabilistic interpretation). Thus, it is possible to argue that, within an adversarial system governed by technologically ambivalent procedures, 'cross-examination and the legal rules of evidence operate only as recipes for obfuscation', restricted to questions of interpretation and blind to the substantive scientific content of the preceding investigation and evaluation.

On the contrary, a rigorously sociological approach - one informed by legal realism requires that we follow the evidential trajectory of DNA profiling, from the very beginning of its journey - as a raw material sample - to its disposal in the courtroom. Through adopting a socially constructivist perspective, we may attempt to isolate, and better understand, the complex of interposing influences and processes that shape the production of biological evidence. Each phase of that evidential trajectory (from the collection and stabilisation of trace samples to their conversion into graphical representations and statistical probabilities) revolves around material objects and visual representations. Therefore, by necessity, research in this area must progress through a consideration of the central role of artefacts, and visual representations, in mediating forensic-scientific communication.

Any study of forensic knowledge production must also provide an account of forensic expertise. Why does the law look to science in order to provide expert evidence with which to guide and assist the court in order to aid the trier-of-fact in their deliberations? Clearly, the law considers that knowledge derived from expert interdisciplinary collaboration is of a higher quality than that which could be derived from lay, intradisciplinary analysis. That belief is consistent with a general assertion of quality (some say assumption), which is frequently made with regard to interdisciplinary knowledge claims. ${ }^{2}$ It is often claimed that interdisciplinarity leads to better quality outputs and to greater impact. This is only partially true. If interdisciplinarity is done correctly it can lead to significant gains. If it is done badly it can lead to the 'enslavement of one domain of knowledge production to another' 3 and the instrumental use of interdisciplinary knowledge claims, which are largely devoid of context. What I hope to demonstrate, through my empirical research, is a way in which we can more readily differentiate between productive practices and unproductive, instrumental practices and, thereby, produce higher quality outputs, with more consistency, whilst avoiding the pitfalls. Socio-legal enquiry across disciplinary boundaries also offers a reflexive opportunity to recognise, and account for, the normative philosophical perspectives which underpin these practices. Predictably, my work derives its theoretical underpinnings

1 S Jasanoff, Science at the Bar: Law, Science and Technology in America (Harvard University Press) 1995.

2 See J T Klein, Crossing Boundaries: Knowledge, Disciplinarities and Interdisciplinarities (University of Virginia Press 1996).

3 M King, 'The Truth about Autopoiesis' (1993) 20(2) Journal of Law and Society 218-36. 
from both science and technology studies, and Teubner's theory of legal autopoiesis. ${ }^{4}$ As Dwyer states:

The idea that society can be made up of a number of systems of discourse, which may recognise one another's existence, but which cannot fully engage in one another's discourse, provides an attractive background against which to explore the relationship between social systems, and in particular between law and other systems, such as medicine, science and economics. ${ }^{5}$

Needless to say, forensic-scientific knowledge production does not occur solely within the rarefied atmosphere of the laboratory. The evidential trajectory carries material samples across contested terrain, where it is exposed to economic cross-winds and subjected to the constant interposition of policy and governance factors. The problem, therefore, is not to attempt to show whether, and to what extent, forensic expertise (as enacted through the analysis and interpretation of visual DNA profiles and the series of translations required to turn raw material samples into Bayesian statistical outputs) is shaped by differing policy, cultural and socio-economic factors but, rather, to determine the extent to which such factors shape the contexts within which the expert is called upon to make, and to justify his or her decisions. And, in attempting to address these issues, my research draws on both social constructionism and Foucaultian theories of governmentality. ${ }^{6}$

Moving from theory to practice, it became clear from an early stage that the completion of a thorough socio-legal account of the construction of DNA-profiling evidence would require a significant level of comparative empirical research, not least due to the ways in which scientific realist accounts of forensic-scientific practice may serve to obfuscate the contingent and situated nature of evidence construction. The initial phase of the investigation comprised a series of visits to forensic science providers (FSPs) in order to observe participants and to conduct interviews. For instance, the subject of the primary case study was Forensic Science Northern Ireland (FSNI), a public sector forensic science provider that operates as an agency within the Northern Ireland Department of Justice. FSNI acts as a primary service provider to the Police Service of Northern Ireland (amongst others). This FSP offers a diverse array of forensic services 'under one roof', including DNA profiling and forensic casework.

Field data capture began in early 2014 and involved a series of visits to the agency's premises in Carrickfergus, Northern Ireland. There, I was able to observe research participants, and to conduct a series of semi-structured interviews with a heterogeneous cohort of staff members. These actors - who represented a diverse array of functions and specialisms - include the chief executive, directors of laboratory and reporting services, lead scientists responsible for biological examination and reporting, and the custodian of the Northern Ireland DNA Database. In addition, I was able to engage with - and to interview - staff members responsible for auxiliary and administrative functions, including quality assurance and business enhancement.

4 See N Luhmann, 'Operational Closure and Structural Coupling' (1992) 13(5) Cardozo Law Review 1434; and L P Luisi, 'Autopoiesis: A Review and a Reappraisal' (2003) 90 Naturwissenschaften 49-59. Also, G Teubner (ed), Autopoietic Law: A New Approach to Law and Society (Walter de Gruyter 1988) and Law as an Autopoietic System (Basil Blackwell1993); M King and F Kaganas, 'The Risks and Dangers of Experts in Court' (1998)1 Current Legal Issues 221-42; M King, 'An Autopoietic Approach to the Problems Presented by Parental Alienation Syndrome' (2002) 13 Journal of Forensic Psychiatry 609-35; King (n 3); and M King, 'The Construction and Demolition of the Luhmann Heresy' (2001) 12(1) Law and Critique 1-32.

5 D Dwyer, The Judicial Assessment of Expert Evidence (Cambridge University Press 2008) 124.

6 G Burchell, C Gordon and P Miller, The Foucault Effect: Studies in Governmentality (University of Chicago Press 1991). 
Fieldwork was extended to encompass a heterogeneous group of associated institutional actors whose interactions help to shape the co-production of forensic evidence. These included members of the judiciary and the legal profession, alongside staff at the Northern Ireland Public Prosecution Service, whose 'Speeding Up Justice' Department provided raw quantitative data, relating to the Indictable Cases Pilot Scheme, specifically for analysis and inclusion in the primary case study.

Data derived from these studies was largely textual and descriptive, consisting of notes and transcribed interviews. Despite attempting to expand the scope of my exploration of DNA-profiling evidence to include its processing within the laboratory, I was aware of an important missing element: the ultimate effect of the forensic product on the trier-of-fact. Therefore, I welcomed the opportunity to participate in creative methodological practices, which might facilitate the generation of serendipitous insights into the probabilistic representation of forensic evidence: practices and approaches which would allow participants to draw reflexive, sensitive and meaningful insights, which are both subjective and aleatory and which help to expose different aspects of the field data, allowing the researcher to place it in a meaningful socio-legal context. This need was met through the process of socio-legal model-making and through my participation in the Pop-Up Museum of Socio-Legal Objects.

\section{The DNA collection kit as a socio-legal object}

It should be clear from the above discussion that material objects play an important role in the study of the co-production of forensic-scientific knowledge claims. In the case of the DNA collection kit, the focus on sterility, a recordable chain of evidence, and evidence of unauthorised contact accords with a scientific-realist perspective and implies that any loss of evidential value can only stem from a derogation from administrative protocols. Crucially, this perspective fails to account for the socially constructed nature of DNA profiling (and associated forensic techniques).

With its focus on sterility and regulatory objectivity, the swab stick may be viewed as a procedural prompt: the means through which institutional actors enact, and reaffirm, their belief in 'the forensic imaginary'. The 'forensic imaginary' is outlined by Williams, ${ }^{7}$ and rests upon a commitment to two principles. The first of these is the assertion that all objects are unique, and that it is possible to capture the unique identifiability of any object (whether or not tied to an ineradicable bodily substrate). The second principle is encapsulated in the proposition - widely attributed to the French scientist Edmond Locard - that 'exchange always happens'.

... whenever individuals make physical contact with other individuals, or enter and leave defined physical spaces, a (usually unintentional) transfer of varying amounts of matter - inert and vital material takes place between the parties and places involved. ${ }^{8}$

The phenomenon attains a special resonance in the current context, given that FSNI's new 'high care' laboratory facility will 'be known as the Locard Building, in reference to the "founding father" of forensic science'?

Recourse to the 'forensic imaginary' may serve a particular purpose within the criminal justice system. As Williams states:

7 R Williams, 'DNA Databases and the Forensic Imaginary' in R Hindmarsh and B Prainsack (eds), Genetic Suspects: Global Governance of Forensic DNA Profiling and Databasing (Oxford University Press 2010)

8 Ibid 134.

9 Edmond Locard is credited as the progenitor of modern forensic scientific practices, having coined the phrase, 'Every contact leaves a trace'. See analytical discussion, above. 
. . the imaginary has been carried in 'images, stories and legends' (Taylor 2004:

23) ... and it has contributed hugely to the willingness of governments to fund forensic science developments and ambitions. ${ }^{10}$

Those whose task it is to craft criminal justice policy, and to alleviate public concerns, often seek recourse to 'the demonstrably effective use of current and emergent technologies': ${ }^{11}$ techniques which are deemed capable of capturing, knowing and recording, individuality and of anchoring members of suspect populations to an inscription derived from a stable and ineradicable biological substrate. However, these principles - upon which the 'forensic imaginary' is founded - are demonstrably ambiguous and vulnerable to criticism and revision.

Thus, from a research perspective, the DNA collection kit may represent a somewhat ambiguous object. While it serves to capture the identity of suspect populations, its representations are limited to one part of the evidential trajectory and fail to capture the sequence of translations, which convert raw biological material into statistical probabilities. It is static as opposed to dynamic and serves as a discrete focus for reflection rather than a point of departure on an interdisciplinary process. A brief discussion of the 'transfer and persistence' problem may serve to illustrate the inherent limitations and ambiguities of the DNA swab collection stick.

'Transfer and persistence' issues represent a growing problem for DNA-profiling experts, whose technologies are now so sensitive that they routinely report 'mixed' samples, including deposits made indirectly through intermediate contacts and lowtemplate DNA, shed naturally by individuals, and subsequently spread through contact and dispersal. In many cases, scientists can de-convolute mixed samples using their expertise (often with the aid of complex computer algorithms). The de-convoluted results may reveal a major contributor and one - or more - minor contributors, all of whose profiles may be complete or partial.

However, the evaluative problems are not limited to attribution. While individual profiles may be 'matched' to individuals on the DNA database - with probabilities in the order of one in one billion - the resulting evidence may be effectively neutralised by the issue of the transfer and persistence of DNA deposits across multiple surfaces. The interposition of such issues shifts the focus of analysis, such that the courts should no longer address themselves to the question of 'To whom does this DNA sample belong?' The salient question becomes, 'How did this DNA sample come to get here?' Thus, while the collection kit may serve a useful purpose within a fairly rudimentary context, the resulting probabilistic evidence (in the order of one billion to one) may be simultaneously compelling and meaningless. The challenge therefore, was to experiment with socio-legal modelling in order to reveal the dual nature of probabilistic evidence.

\section{Socio-legal modelling}

I had previously embarked upon a consideration of the ways in which probabilistic evidence is presented to jurors, alongside a consideration of the ways in which expert communication might be improved through visual translation. I was aware that the terms 'translation' and 'ratio' are common to both forensic biology and engineering. In

10 Williams (n 7) 135.

11 In his 2014 Kalisher Lecture to the Criminal Bar Association, the Lord Chief Justice, the Rt Hon The Lord Thomas of Cwmgiedd, expressed concerns regarding the potential of new, or complex, scientific developments to tarnish the status of forensic DNA profiling. Lord Thomas identified the "challenge for all ... advocates and judges: to manage the presentation and testing of forensic evidence in such a way as to avoid fatally undermining confidence'. 


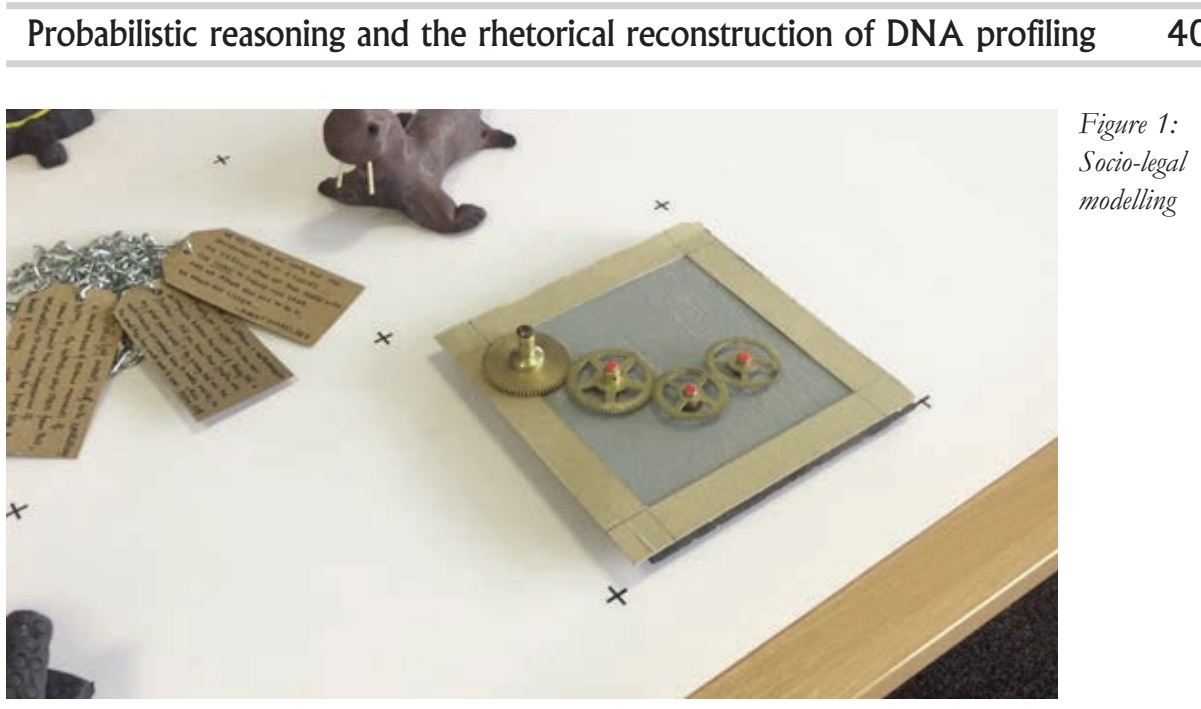

engineering, the terms are deployed in reference to gear wheels, through which power is translated (in accordance with a particular ratio) in an effort to convert a rotational input to one of greater or lesser magnitude.

The challenge was to capture the persistent fallacy of scientific realism, as iterated through forensic-scientific knowledge production: that a measurable input leads to a measurable output - an output which is both predictable and consistent. Therefore, I decided to mount a series of four interconnected brass clock wheels onto a wooden plinth. The series of wheels were mounted on a piece of grey lacquered wood. Introducing a bio-mechanical input to the initial wheel would turn all successive gear wheels. Further, the wooden plinth was surrounded by a black border to represent the 'black-boxing' of the intermediating series of translations.

The results were as surprising to me as they were to my audience. In order to express a standard likelihood ratio, in the order of one billion to one (an order of magnitude commonly encountered when dealing with DNA attributions on the source and subsource level), an output gear wheel of 38 millimetres diameter (as used in my socio-legal model) would need to achieve one billion rotations for every single complete turn of the input wheel. What size, then, would the input wheel have to be? According to my calculations, the wheel would have to be $12,095 \mathrm{~km}$ in diameter. ${ }^{12}$ Clearly, such an exercise would be unfeasible. However, the ability to render such ratios in visual terms - however astronomical - led to valuable insights into the use of statistics and their place in the courtroom. It raised questions regarding the relative importance of consistent and predictable inputs and outputs versus clarity and utility. These considerations will form the conclusion of this article. However, it is first worth reviewing the practice of sociolegal model-making.

\section{Socio-legal modelling as reflexive praxis}

Throughout each stage of the socio-legal model-making process I was encouraged to reflect mindfully on the impact of this unique methodology on my work as a legal researcher. A complete - but brief - consideration of each stage is provided below. 


\section{CHOOSING AN OBJECT}

During this preliminary stage I was forced to approach my research from new perspectives. The process invited me to reconsider the objects of legal enquiry and law's relationship with other disciplines. This process of reconsideration and exploration has been useful in establishing a more nuanced understanding of the research topic and themes.

\section{Making a MOdel of THE OBJeCT}

This was a particularly enlightening activity, which enabled me to focus on the necessity of entering into a 'hands-on' physical relationship with the model-making materials and of confronting the limitations of the original object (in particular its inability to represent a dynamic process). I was guided in this activity by my knowledge of the research process but also - to a degree - open to intuition as I worked with the materials.

\section{WRITING YOUR OBJECT-BASED COMMENTARY}

Writing began with note-taking. The process of writing about my thoughts and ideas, my concerns and experiences, enabled me to re-interpret my research project in a comprehensive and systematic way: one that took account of my life history and subjective experiences. It also benefited me to engage in a self-directed activity that enhanced the process of reflexively reviewing the development of my research.

In the course of my object-based reflective writing I had to ask myself philosophical questions about my orientation to the world, exploring my fundamental assumptions and interrogating the values and beliefs that underpin them. In this way I was able to better understand - and account for - 'researcher positionality'. I believe that this subjective interrogation of my own position enabled me to better understand the needs of jury members and legal triers-of-fact when confronted with unfamiliar scientific evidence. In particular, it raised questions regarding the appropriateness of strong match probabilities (of one billion to one) within a forum which - in civil procedural terms - requires the trier-of-fact to arrive at a judgment on the mere balance of probabilities. The process raised concerns about the dehumanising power of statistical information and the potential for strong match probabilities to provide seemingly conclusive answers which may prevent jury members from entering into a more detailed consideration and evaluation of the entirety of the evidence.

\section{DisPlaying YOUR MODEL, TOGETHER WITH EVERYONE ELSE'S, DURING THE THEME SESSIONS}

This enabled me to see how my model sat alongside others and I was able to reflect on our shared challenges and common goals. It also enabled comparisons to be made between different approaches using a range of materials drawn from alternative practices. I was able to reflect on the degree to which the mode of practice, and the materials used, embodied the topic of discussion. My own model attempted to reflect a dynamic mathematical and scientific practice. Thus, it used moving gear wheels mounted on a piece of wood. As such, its engineering reflected the use of scientific models to measure elements of a theory or design process. Other participants chose more artistic forms of expression. Some were intricately patterned, others amorphous. Some chose to use evocative documents and graphical representations. The range of approaches made me consider alternative methods of model-making. Next steps will be to attempt a series of different approaches using a range of materials in order to look for points of convergence and to enable me to benefit from a range of perspectives. 


\section{REFERRING TO THE PHYSICAL MODEL AND/OR THE IMAGE OF YOUR ORIGINAL OBJECT IN YOUR PRESENTATION}

The presentation enabled me to better gauge those aspects of the design process which resonated with a legal audience and those more abstruse elements of my presentation which achieved less impact. The heart of my presentation involved a discussion of the scale of probabilities routinely used in the courtroom. Statistical evaluations in the order of one billion to one are routinely encountered, based upon the estimated frequency of a particular DNA profile within a known population. However, these have been shown to contribute little to the court's understanding of the evidential significance of a reported DNA 'match' and could even prove prejudicial. Therefore, these are often replaced by statistical evaluations based on Bayesian theories. The Bayesian approach to inferential reasoning is organised around the production of 'likelihood ratios' from pairs of propositions. The forensic scientist constructs these propositions, which correspond to likely scenarios and typical explanations. The Bayesian approach requires the scientist to ask a particular set of questions regarding the object of analysis. As such, Bayesian reasoning has be likened to an 'inference engine', capable of being updated in order to assimilate new contextual information. However, this dependency on background information creates a relationship of forensic reliance on the police or prosecutor, in order that the latter may provide the necessary context. This process of construction, communication and representation is known as case assessment and interpretation (CAI), an approach pioneered by the UK Forensic Science Service and now used by commercial and state-run laboratories across the globe. Nonetheless, the use of CAI remains limited to serious cases, with non-contextual match probabilities still routinely used in relation to so-called 'volume crimes'.

The ability to visualise the match probability ratios, using a model and visual aids, was particularly helpful and feedback was encouraging. It enabled participants to explore the meaning and effect of strong match probabilities. I intend to extend this exploration, perhaps attempting to develop a visual aid that enables jury members (and other triersof-fact) to better visualise probabilistic evidence in the courtroom.

\section{SEEING/HEARING OTHER PRESENTERS USING THEIR OBJECT/MODEL TO MAKE A LEGAL POINT}

It was fascinating to hear Brechtian performativity discussed alongside Artaud's theatre of cruelty. Once again, the styles of presentation varied and enabled reflective consideration of the different approaches but also of the common emergent themes.

\section{SeEING the Pop-Up Museum PROJeCted over LUNCh/TEA At SLSA 2017}

I engaged with other members of the Socio-Legal Studies Association (SLSA) and viewed the Pop-Up Museum. I discussed the visualisation process with other postgraduate research students from my institution, actively listening to their stories and experiences, discussing the relative strengths and weaknesses of different methodological approaches, and comparing outcomes. I found it worthwhile to listen to their experiences with visual methods - their successes, frustrations and initial failures - as these were not dissimilar to my own.

\section{SeEING THE MOdels Displayed tOgether at afternoON TEA}

The opportunity to view the models together led to a fruitful discussion with other delegates. We considered the ways in which incorporating images of models into our research data might aid understanding and enable the creation of previously unarticulated constructions of the research process. 


\section{Seeing your object as part of the online Pop-Up Museum Collection}

Seeing my object online enabled a more objective consideration of the need for all researchers to be reflexive about power dynamics and to be mindful of their role in coconstructing the research environment.

\section{SEEING YOUR OBJECT AS PART OF THE FOLDED PAPER GUIDE TO THE COLLECTION}

This was a particularly interesting element of the process, which enabled me to consider the ways in which certain objects are selected, curated, documented and presented. Being asked to fold the programmes helped, as it felt as though we were also constructing the fixed documentary presentation of our objects. It provoked some consideration of the ways in which objects are selected, indexed, catalogued and presented. This provided a degree of isomorphism between the design process and the substance of my doctoral study (the selection, cataloguing and presentation of evidential samples).

\section{Seeing the Pop-Up Museum on Twitter}

This led to an intense reflection on certain aspects of the process. It demonstrated that researchers may, when necessary, adopt a more flexible approach: one which is capable of providing insights which may otherwise have remained obfuscated. It clarified nascent thoughts regarding the rhetorical aspects of scientific argumentation and the instrumental uses of probabilistic arguments within the courtroom.

\section{Seeing the Pop-Up Museum Set out as an experiment on the ECONOSOCIOLEGAL.WORDPRESS.COM BLOG POST}

I was able to place this project in the context of (econo-socio-legal) visual methods in general: to evaluate their use, consider the degree to which such methods may reduce power imbalances in the field, gauge their potential to meaningfully engage others in the research process, and help to overcome barriers (both cognitive and epistemological).

\section{CONCLUSIONS}

The socio-legal modelling process opened up a conceptual space which allowed me to explore themes that I had hitherto been unable to develop due to their seeming intangibility. Thus, it provided tangible clarity and coherence. The process allowed me the opportunity to explore the meaning of probabilistic evidence, to overcome the confines of arid mathematical theorising and to expose the rhetorical roots of forensic-scientific argumentation.

\section{Incorporation of socio-legal modelling outcomes: scientific rhetoric and 'the mathematical sublime'}

It was only during the final stage of the modelling process - the incorporation of insights derived from the process into the research project - that its methodological potential, and practical utility, was fully realised.

The modelling process had enabled me to surmount the realist account of DNA - as a universal, ineradicable substrate, which encodes bio-individuality - and to perceive the limits of translation and the problems associated with the Bayesian probabilities. It invited me to ask fundamental questions about the place of astronomical statistical ratios in a legal arena which is more accustomed to probabilistic calculations taking place on the level of reasonable doubt, or the mere balance of probabilities. I was drawn to make comparisons on the aesthetic level, particularly with Piranesi's engravings of carceri 
(prisons), in which tiny stricken figures populate dungeons of vast dehumanising proportions. Of note, in light of the above discussion, is Piranesi's rendering of 'The Giant Wheel', with its echoes of Foucauldian disciplinary power. And, just as Piranesi's carceri were 'capricci' - whimsical aggregates of monumental architecture and ruin - so the seemingly robust facade of statistical evidence appeared equally empty of purpose.

However, it is not the use of probabilistic information in and of itself but, rather, the magnitude of the resulting ratio that had been rendered problematic. The use of ratios in the order of billions, tending towards the infinite, now appeared more emblematic of the Kantian mathematical sublime than of expertise and rational deliberation.

Kant's ${ }^{13}$ taxonomy of aesthetic sensibility divides the sublime into the mathematical and the dynamical, the former being concerned with vast magnitude while the latter is concerned with vast natural power. The latter achieves sublimity through its disunity and formlessness, which acts against understanding and overwhelms the imagination. On the contrary, the distinctive feature of the mathematical sublime is its 'absolute' greatness, in relation to an objective standard: infinity. This greatness is beyond comparison, hence sublime. Sublime phenomena cannot be measured by an extrinsic standard and must therefore be judged on their own terms. While natural objects, judged by their physical dimensions, may be deemed great or small in reference to some other object of a different magnitude, the sublime cannot be judged by such subjective standards. ${ }^{14}$ Therefore, the sublime, in its absolute greatness, must be a function of reason, in terms of its internal logic, since it does not presuppose an external standard.

As Smith ${ }^{15}$ suggests, the mathematical sublime is especially concerned with the importance (or unimportance) of infinity as a measure against which phenomenal magnitudes are compared'. Apprehension of the mathematical sublime rests upon an aesthetic judgement, which is largely intuitive and decidedly non-cognitive, yet displays a particular relation to cognition, which Kant describes as an embodied purposiveness. This 'subjective formal purposiveness' is - in the instant case - related to probabilistic concepts but is satisfied by their mere presentation and the resulting intuition that such presentation accords with reason. It therefore serves as a catalysing agency, which furnishes the law with the strategic dimensions of forensic-scientific reasoning. Indeed, we may be entitled to look upon probabilistic forensic reasoning as a genre of scientific rhetoric. One which, when applied to DNA-profiling techniques, has proven overwhelmingly successful in provoking an aesthetic response. These results support James Boyd White's assertion that 'law is rhetoric, and rhetoric is law'.

Through reframing interdisciplinary forensic-scientific reasoning, as an exercise in rhetorical persuasion, the instability and indeterminacy of legal judgment becomes more apparent. The efforts of the courts and the judiciary to reconcile the knowledge claims of a variety of institutional actors - each of whom embody disparate epistemological traditions and whose normative values are frequently divergent, if not diametrically opposed - is opened up to a critique which reveals the endemic contingency of interdisciplinary co-production.

13 Immanuel Kant, Critique of Judgment (J H Bernard (trans), Macmillan 1951).14

14 See, for example, $R v$ Sean Hoey [2007] NICC 49, in which the court heard expert testimony that the molecules used in Low Copy Number DNA were the size of a millionth of a grain of salt.

15 S D Smith, 'Kant's Mathematical Sublime and the Role of the Infinite: Reply to Crowther' (2015) 20(1) Kantian Review 99-120. 
